\title{
The Distribution of Languages
}

\section{in Hermes 1-38 (1988-2007)}

\begin{tabular}{|c|c|c|c|c|c|c|c|}
\hline HERMES & DANISH & NORWEGIAN & SWEDISH & ENGLISH & GERMAN & FRENCH & SPANISH \\
\hline 1 & $18 / 235$ & & & & & & \\
\hline 2 & $4 / 172$ & & & $2 / 10$ & $1 / 17$ & & \\
\hline 3 & $9 / 128$ & $2 / 26$ & & $7 / 98$ & $2 / 32$ & & \\
\hline 4 & $5 / 55$ & $1 / 13$ & & $1 / 16$ & $1 / 16$ & $2 / 32$ & \\
\hline 5 & $9 / 65$ & & & $3 / 58$ & $1 / 13$ & & \\
\hline 6 & $4 / 19$ & & & $7 / 92$ & $5 / 63$ & & \\
\hline 7 & $9 / 47$ & & & $5 / 38$ & $3 / 54$ & $1 / 21$ & \\
\hline 8 & $3 / 33$ & & & $5 / 47$ & $4 / 34$ & $1 / 5$ & \\
\hline 9 & $3 / 28$ & & & $7 / 92$ & $1 / 17$ & $3 / 58$ & \\
\hline 10 & $4 / 56$ & & & $5 / 53$ & $3 / 19$ & $1 / 8$ & \\
\hline 11 & $7 / 39$ & & & $6 / 89$ & $1 / 9$ & & \\
\hline 12 & $8 / 39$ & & & $13 / 153$ & $1 / 8$ & & \\
\hline 13 & $14 / 122$ & & & $19 / 192$ & $1 / 4$ & $1 / 19$ & \\
\hline 14 & $13 / 106$ & $1 / 20$ & & $8 / 94$ & $3 / 27$ & & \\
\hline 15 & 9/99 & & & $6 / 129$ & & $1 / 22$ & \\
\hline 16 & $9 / 32$ & & & $4 / 66$ & $2 / 58$ & $6 / 88$ & \\
\hline 17 & $10 / 70$ & & & $8 / 131$ & $3 / 53$ & & \\
\hline 18 & $6 / 51$ & & & $5 / 89$ & $7 / 79$ & & \\
\hline 19 & $18 / 144$ & & & $10 / 93$ & $1 / 6$ & $2 / 18$ & \\
\hline 20 & $19 / 155$ & $1 / 19$ & & $4 / 64$ & $1 / 6$ & & \\
\hline 21 & $10 / 146$ & & & $3 / 36$ & $2 / 16$ & & \\
\hline 22 & $4 / 15$ & & & $6 / 65$ & $5 / 71$ & $2 / 21$ & \\
\hline 23 & $5 / 46$ & & & $9 / 106$ & $4 / 64$ & & \\
\hline 24 & $3 / 26$ & & & $7 / 138$ & $4 / 22$ & & \\
\hline 25 & $2 / 41$ & & & $10 / 123$ & $2 / 24$ & & \\
\hline 26 & $7 / 51$ & & & $6 / 93$ & $3 / 17$ & $1 / 4$ & \\
\hline 27 & $6 / 99$ & & & $6 / 102$ & & & \\
\hline 28 & $2 / 33$ & & & $7 / 123$ & $3 / 41$ & & \\
\hline 29 & $15 / 153$ & & & $2 / 17$ & $7 / 113$ & & $1 / 20$ \\
\hline 30 & $9 / 147$ & & & $3 / 49$ & & $1 / 17$ & \\
\hline 31 & $4 / 39$ & & & $12 / 165$ & & & \\
\hline 32 & $1 / 33$ & & & $10 / 186$ & & & \\
\hline 33 & $4 / 73$ & & & $1 / 1$ & $5 / 94$ & & \\
\hline 34 & $3 / 41$ & & & $8 / 153$ & $1 / 8$ & $3 / 63$ & \\
\hline 35 & $6 / 92$ & & $1 / 13$ & $5 / 62$ & $7 / 78$ & & \\
\hline 36 & $6 / 58$ & & & $5 / 73$ & $4 / 58$ & & \\
\hline 37 & & & & $8 / 112$ & $2 / 16$ & & \\
\hline 38 & & & & $12 / 172$ & $1 / 32$ & & \\
\hline Total & $278 / 2788$ & $5 / 78$ & $1 / 13$ & $245 / 3380$ & $91 / 1169$ & $25 / 376$ & $1 / 20$ \\
\hline
\end{tabular}

Hermes - Journal of Language and Communication Studies no 39-2007 


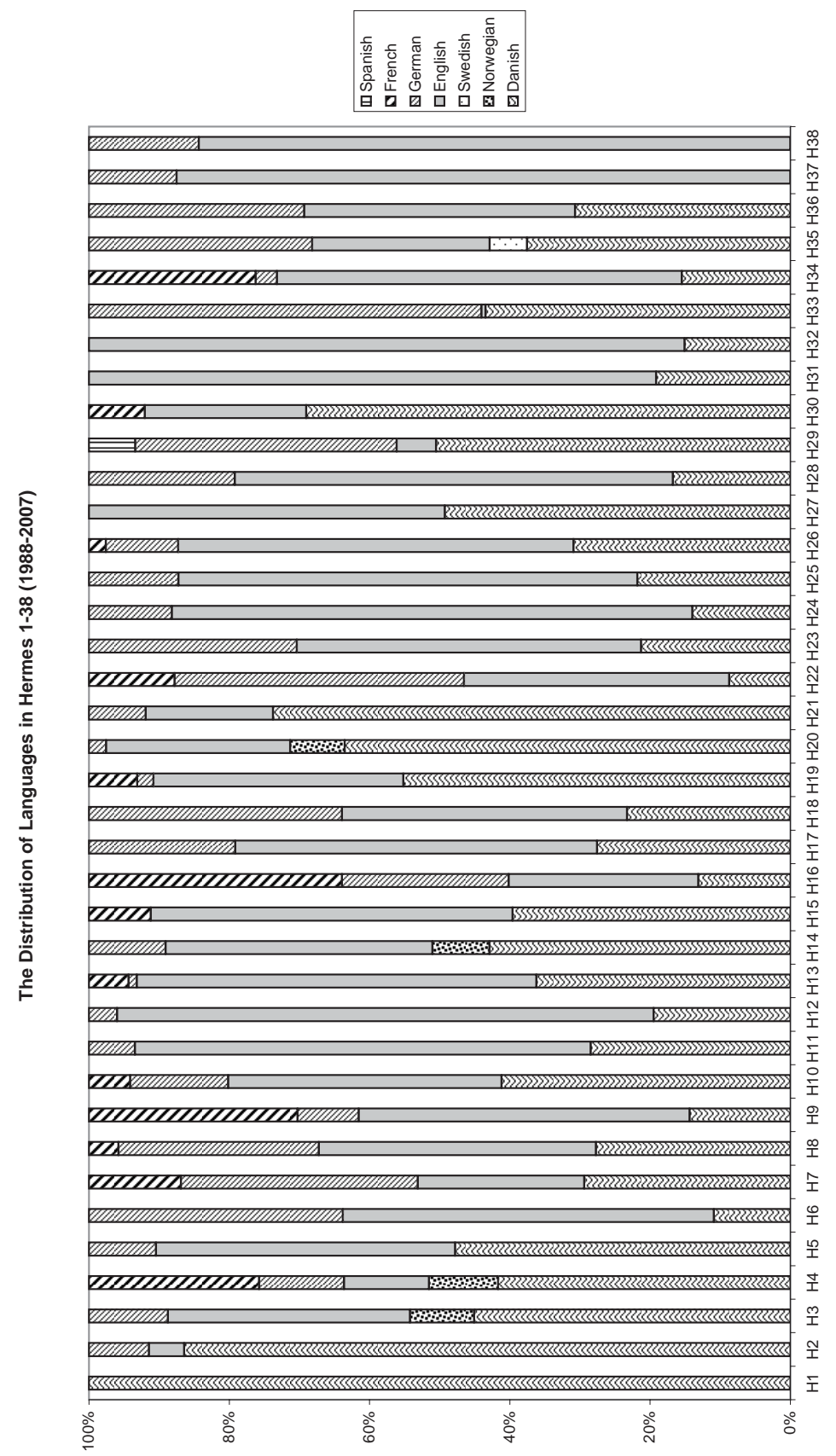

